\title{
Antioxidant and Anti-Inflammatory Strategies Based on the Potentiation of Glutathione Peroxidase Activity Prevent Endothelial Dysfunction in Chronic Kidney Disease
}

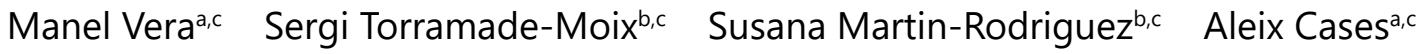 \\ Josep M Cruzado ${ }^{d, e} \quad$ Jose Rivera ${ }^{f}$ Gines Escolar ${ }^{b, c} \quad$ Marta Palomo ${ }^{b, c, g, h}$ \\ Maribel Diaz-Ricart ${ }^{\mathrm{b}, c, g, h}$ \\ aNephrology Department, Hospital Clinic of Barcelona, Barcelona, 'Hematopathology Department, \\ Biomedical Diagnosis Centre (CDB), Hospital Clinic of Barcelona, Barcelona, Institute of Biomedical \\ Research August Pi i Sunyer (IDIBAPS), University of Barcelona, Barcelona, "Institut Hemodiálisis \\ Barcelona, Barcelona, eNephrology Department, Bellvitge Hospital, IDIBELL, L'Hospitalet de Llobregat, \\ Barcelona, 'Servicio de Hematología y Oncología Medica, Hospital Universitario Morales Meseguer, \\ Centro Regional de Hemodonación, Universidad de Murcia, IMIBArrixaca, Murcia, 9Josep Carreras \\ Leukaemia Research Institute, Hospital Clinic/University of barcelona Campus, Barcelona, hBarcelona \\ Endothelium Team, Barcelona, Spain
}

\section{Key Words}

Endothelial dysfunction - Uremia - Antioxidants - Flavonoids - Glutathione peroxidase • Ebselen $\cdot \mathrm{N}$-acetylcysteine

\footnotetext{
Abstract

Background/Aims: Accelerated atherosclerosis in chronic kidney disease (CKD) is preceded by endothelial dysfunction (ED), which exhibits a proinflammatory and prothrombotic phenotype and enhanced oxidative stress. In this study, the effect of several compounds with anti-inflammatory and/or antioxidant properties on uremia-induced endothelial dysfunction has been evaluated in an in vitro model. Methods: Endothelial cells (ECs) were exposed to sera from uremic patients in the absence and presence of the flavonoids apigenin, genistein and quercetin, the antioxidant enzyme mimetics (AEM) ebselen (glutathione peroxidase mimetic), EUK-134 and EUK-118 (both superoxide dismutase mimetics), and the pharmacological drug $\mathrm{N}$-acetylcysteine (NAC). We explored changes in the expression of adhesion receptors on the cell surface, by immunofluorescence, the production of radical oxygen species (ROS), by fluorescence detection, and the activation of signaling proteins related to inflammation, by

M. Palomo and M. Diaz-Ricart contributed equally to this work.

\begin{tabular}{ll}
\hline Dr. Aleix Cases & Nephrology Unit, Hospital Clínic \\
& Villarroel 170, 08036 Barcelona (Spain) \\
& Tel. 34-93-227 54 47, Fax 34-93-227 54 98, E-Mail acases@clinic.ub.es
\end{tabular}
}


both a phosphospecific antibody cell-based ELISA and immunoblotting techniques. Results: Uremic media induced a significantly increased expression of ICAM-1, overproduction of radical oxygen species (ROS) and activation of p38 mitogen activated protein kinase (p38MAPK) and Nuclear Factor $\kappa B(N F \kappa B)$ in ECs. Quercetin, the AEM and NAC showed a significant inhibitory effect on both ICAM-1 expression and ROS generation $(p<0.05)$. All the compounds reduced p38MAPK activation, but only the AEM, especially ebselen, and NAC, both potentiating the glutathione peroxidase pathway, also inhibited NFkB activation. These two compounds were capable of increasing endothelial glutathione levels, especially in response to uremia. Conclusion: Our results indicate that the potentiation of the antioxidant pathways can be an effective strategy to improve endothelial dysfunction in uremia and a potential target to reduce the cardiovascular risk in this population.

(C) 2018 The Author(s)

Published by S. Karger AG, Basel

\section{Introduction}

Endothelial dysfunction (ED) is considered to be the first step in the development and progression of atherosclerosis and has been observed in many disorders associated with increased cardiovascular morbidity and mortality [1-3]. Chronic kidney disease (CKD), is a well-recognized example of a chronic multisystemic disorder associated with an enhanced cardiovascular risk [4]. There is clinical $[5,6]$ and experimental evidence of an inflammatory state and enhanced oxidative stress in CKD, both major contributors to the progression of cardiovascular disease (CVD) in uremia [7, 8].

Oxidative stress has been proposed to play a major role in the development of ED through the production of radical oxygen species (ROS), which activate intracellular signaling pathways, including protein kinases, such as mitogen-activated protein kinases (MAPK) [9]. Moreover, the uremic endothelium exhibits a proinflammatory phenotype, with an increased expression of adhesion molecules and production of proinflammatory cytokines, which have been reported as key processes in endothelial activation and damage $[10,11]$.

Using an in vitro model, our group has previously characterized the CKD-induced endothelial damage $[12,13]$. Exposure of endothelial cells (ECs) to growth media containing sera from uremic patients results in morphological alterations, increased proliferation, enhanced thrombogenicity of the extracellular matrix, and increased expression of diverse proteins related to inflammation, such as high mobility group box-1 protein (HMGB1), and to oxidative stress, such as superoxide dismutase (SOD) and glutathione peroxidase (GPx) [14]. Moreover, in recent studies we have demonstrated that these changes are associated with enhanced ROS production, the activation of signaling pathways related to cell stress and inflammation, such as the p38MAPK and the transcription factor nuclear factor- $\kappa \mathrm{B}(\mathrm{NF} \kappa \mathrm{B})$ [15], as well as to enhanced innate immunity, as seen with toll-like receptor 4 (TLR4) and the NALP3 inflammasome [16].

On the other hand, lipid-lowering therapy with statins or the use of renin-angiotensin system inhibitors (such as ACE inhibitors or angiotensin receptor blockers) that have proven its efficacy in reducing CVD in the general population, as well as subsets of high cardiovascular risk patients, such as diabetics or coronary artery disease patients, have failed to prove a benefit in dialysis patients [17-19]. Thus, there is a need for alternative therapies able to reduce the cardiovascular complications in this population. Strategies that improve ED in advanced CKD or ESRD may be a promising therapeutic approach.

Polyphenolic compounds, found in fruits and vegetables, have demonstrated both antiinflammatory and antioxidant properties [20]. Different studies assert that a diet rich in flavonoids is associated with a reduction in the cardiovascular risk, suggesting that these compounds might have potential protective effects on the endothelium [21]. There is evidence indicating that mammalian cells activate intrinsic antioxidant defense mechanisms, such as antioxidant enzymes, in response to stress molecules induced by ROS production. Recently, synthetic compounds with antioxidant enzyme mimetic activity have emerged as novel antiinflammatory and antioxidant agents potentially useful in different clinical situations such 
as stroke, respiratory infections and diabetes [22-24]. A recent systematic review [25] of clinical trials, assessing the effects of antioxidant therapy in CKD patients, indicates that $\mathrm{N}$-acetylcysteine (NAC) has promising effects by decreasing the levels of oxidative stress markers and in a small study it reduced the risk of cardiovascular events in dialysis patients [26]. Furthermore, NAC improves endothelial dysfunction in dialysis patients [27] and in an in vitro model of uremic dysfunction [28].

The aim of the present study was to investigate the potential protective effect on CKD-induced ED of three flavonoids (apigenin, genistein and quercetin), three chemicallysynthesized compounds with antioxidant enzyme mimetic effect (EUK134, EUK118, and ebselen), and NAC. We have performed the experiments in our well-characterized in vitro model of uremia-induced endothelial dysfunction.

\section{Materials and Methods}

\section{Experimental design}

Endothelial cells (ECs) were exposed to sera samples from uremic patients under peritoneal dialysis $(U, n=16)$ or from healthy donors selected as controls $(C, n=15)$, in the absence and presence of the following pharmacological compounds: the flavonoids apigenin (flavone), genistein (isoflavone) and quercetin (flavonol); the antioxidant enzyme mimetics ebselen (GPx mimetic), EUK134 and EUK118 (SOD mimetics); and NAC, which acts as a donor of cysteine precursors, the substrate for GPx, aimed at glutathione (GSH) restoration [29-32]. Cell viability studies (using the MTT assay) were performed to determine the appropriate compound concentrations. Cells were pretreated with the compounds for $24 \mathrm{~h}$ before and during the exposure to the growth media containing the uremic serum, to evaluate changes in: i) the expression of the cell surface adhesion molecule ICAM-1, ii) the intracellular production of ROS, and iii) the activation of the signal transduction protein p38MAPK and NFkB, by ELISA and Western-Blot techniques.

\section{Patients and sample collection}

End-stage renal disease patients on peritoneal dialysis using biocompatible solutions with low levels of glucose degradation products (GDP) were included. In order to dissect as much as possible uremia from other conditions known to induce endothelial dysfunction, diabetic patients, patients with dyslipidemia and/ or previous cardiovascular disease, current smokers and patients who had had an episode of peritonitis in the previous 2 months were excluded. Patients' characteristics are detailed in Table 1. Sex and age-matched healthy donors, with no previous history of cardiovascular disease, and preserved renal function (eGFR $>90$ $\mathrm{ml} / \mathrm{min} / 1.73 \mathrm{~m} 2$, CKD-EPI formula) were enrolled as controls. Written informed consent was obtained from every healthy donor and patient included in the study. The study was approved by the Ethics Committee of the Hospital Clinic and was carried out according to the principles of the Declaration of Helsinki.

Sera samples were

obtained from each uremic patient and from each healthy donor by centrifugation of nonanticoagulated blood (3000xg, $15 \mathrm{~min}$ ) and immediately stored at $-80^{\circ} \mathrm{C}$ until used. Pools of serum were prepared containing serum samples from different donors / patients, which were used as reagent for the different experiments performed.
Table 1. Main demographic characteristics, biochemical parameters and treatments in healthy subjects (control) and CKD patients

\begin{tabular}{lcc}
\hline Parameter & Control (15) & Uremic (16) \\
\hline Age, years (mean \pm SD) & $57.6 \pm 10.0$ & $62.7 \pm 20.4$ \\
Gender (male/female) & $7 / 8$ & $7 / 9$ \\
Residual renal function (ml/min) (mean \pm SD) & -- & $6.4 \pm 4.7$ \\
Mean time on dialysis, months (mean \pm SD) & -- & $17.6 \pm 8,2$ \\
Serum Albumin (g/dl) (mean \pm SD) & $4.3 \pm 0.3$ & $4.1 \pm 0.6$ \\
Hemoglobin (g/dl) (mean \pm SD) & $12.5 \pm 2$ & $11.8 \pm 1.9$ \\
Leukocytes (109/L) (mean \pm SD) & $7.8 \pm 1.4$ & $8.1 \pm 2.3$ \\
Causes of CKD n (\%) & & \\
Glomerulonephritis & & $2(12.5 \%)$ \\
Interstitial nephropathy & & $1(6.25 \%)$ \\
Polycystic kidney disease & & $3(18.75 \%)$ \\
Obstructive kidney disease & & $1(6.25 \%)$ \\
Nephrocalcinosis & & $3(18.75 \%)$ \\
Unknown & 0 & $6(37.5 \%)$ \\
Hypertension, n (\%) & 0 & $12(75 \%)$ \\
Statin prescription, n (\%) & 0 & $16(100 \%)$ \\
Vitamin D supplementation, n (\%) & 0 & $14(87.5 \%)$ \\
Erythropoiesis stimulating agents, n (\%) & 0 & $9(56.25 \%)$ \\
Inhibitors of the Renin-Angiotensin System, n (\%) & $0.25 \%)$ \\
\hline
\end{tabular}




\section{Cellular Physiology Cell Physiol Biochem 2018;51:1287-1300 and Biochemistry Published \begin{tabular}{l|l} 
DOI: 10.1159/000495540 & (c) 2018 The Author(s). Published by S. Karger AG, Basel \\
www.karger.com/cpb
\end{tabular} \\ Vera et al.: Antioxidants For Uremic Endothelial Dysfunction}

\section{Materials and reagents}

Culture media MEM199, L-glutamine, penicillin/streptomycin, fetal bovine serum (FBS) and accutase were all purchased from Gibco-Life Technologies (NY, US). The 3-(4, 5-Dimethylthiazol-2-yl)-2, 5 Diphenyltetrazolium Bromide (MTT) and the flavonoids apigenin, genistein and quercetin were obtained from Sigma Aldrich (St.Louis, MO, US). The enzyme mimetics ebselen, EUK134 and EUK118 were purchased from Cayman Chemical (MI, US). N-acetylcysteine solution (100 mg/mL) was from Zambon (Barcelona, Spain). The pharmacological compounds were dissolved according with manufacturer protocols, with a final concentration of DMSO $<0.1 \%, \mathrm{NaOH}<0.01 \%$ and $\mathrm{EtOH} 100 \%<0.02 \%$ in culture medium.

The ROS detection reagent 5-(and 6)-chloromethyl-2',7'-dichlorodihydrofluorescein diacetate acetyl ester (CM-H2DCFDA) was purchased from Molecular Probes (NY, USA). ELISA p38MAPK and NFkB p65 kit superArrays were obtained from SABiosciences (MD, USA). Antibodies against phospho-p38 MAPK (thr180/tyr182), phospho-IкB $\alpha$ (Ser35) and $\beta$-actin were from Cell Signaling Technology Inc (MA, US), while the antibody against ICAM-1 was purchased from Millipore (Temecula, CA, US). Sulfosalicylic acid was from Sigma-Aldrich (MO, US) and the commercially available GSH detection kit K0006-F1 was from Arbor Assays (MI, US).

\section{Endothelial cell cultures}

ECs were isolated from human umbilical veins [32] and maintained in Medium 199 supplemented with $100 \mathrm{U} / \mathrm{mL}$ penicillin, $100 \mathrm{~g} / \mathrm{mL}$ streptomycin and $20 \%$ pooled human serum at $37^{\circ} \mathrm{C}$ under a humidified atmosphere with $5 \%$ of $\mathrm{CO} 2$. Culture medium was replaced every $48 \mathrm{~h}$, together with the compounds under study when required. Cells were used between the 2 nd and $3 \mathrm{rd}$ passage.

\section{Cell viability analysis (MTT assay)}

ECs were seeded in a 96-well microplate (10.000 cells/well) and exposed to different concentrations of the selected compounds, as well as to the different vehicles used at maximal concentration $(0.1 \%$ DMSO, $0.01 \% \mathrm{NaOH}$ and $0.02 \% \mathrm{EtOH})$. After incubation, cell viability was examined by using 3-(4, 5-dimethylthiazol- 2-yl)-2, 5-diphenyl-tetrazolium bromide (thiazolyl blue tetrazolium bromide). All procedures were performed in triplicate according to the manufacturer's instructions. The absorbance was measured at 530 $\mathrm{nm}$. According to the results obtained, experiments were performed using the pharmacological compounds under study at the concentrations that exhibited the lowest cell toxicity (less than $10 \%$ of cell death), being: $25 \mu \mathrm{M}$ apigenin, $0.1 \mu \mathrm{M}$ genistein, $1 \mu \mathrm{M}$ quercetin, $5 \mu \mathrm{M}$ ebselen, $1 \mu \mathrm{M}$ EUK134, and $5 \mu \mathrm{M}$ EUK118. NAC was used at a concentration of $10 \mathrm{mM}$, similar to the one used in previous studies [33].

\section{Expression of ICAM-1 on endothelial cell surface}

ECs on 6-well microplates were pretreated with the different compounds for $24 \mathrm{~h}$ and then stimulated with media containing $20 \%$ of pooled sera from the uremic patients or healthy donors (24h), according to previous studies by our group [15, 34]. Cells were fixed with 2\% (for $10 \mathrm{~min}$ ) followed by $4 \%$ (for 10 min) paraformaldehyde in 0.15M PBS, pH $7.4\left(4{ }^{\circ} \mathrm{C}\right)$, blocked with $1 \%$ BSA and incubated with a primary antibody against ICAM-1 (dilution 1:200, $1 \mathrm{~h}$, RT), and a secondary antibody anti-mouse IgG conjugated with Alexa 555 (dilution 1:2000 $1 \mathrm{~h}$, at RT) [15]. Then samples were evaluated by light microscopy (Leica DM4000B, Barcelona, Spain), images captured through a videocamera (Leica DFC310FX, Barcelona, Spain) and the density of labeling calculated by computerized morphometric analysis (ImageJ, National Institutes of Health, Bethesda, Maryland, USA). All procedures were performed in duplicate.

\section{Production of intracellular reactive oxygen species (ROS)}

ROS production was explored by using the ROS detection reagent CM-H2DCFDA. This compound can passively diffuse into cells and it is specifically oxidized into the highly fluorescent dichlorofluorescein (DCF) by ROS. The measure of the fluorescence emitted reflects the intracellular ROS production.

ECs seeded on 24-well plates (TPP, Sigma-Aldrich, MO, US) were preincubated with $10 \mu \mathrm{M} \mathrm{CM-H2DCF-}$ DA ( $\left.37^{\circ} \mathrm{C}, 15 \mathrm{~min}\right)$. Then, cells were washed with PBS $(3 \mathrm{x})$ followed by cell stimulation with pooled uremic serum for $30 \mathrm{~min}$ in the absence and presence of the compounds under study. Intracellular ROS production was monitored by fluorescence microscopy (Leica DM4000B, Barcelona, Spain), images captured through a videocamera (Leica DFC310FX, Barcelona, Spain) and the density of labeling calculated by computerized 


\section{Cellular Physiology Cell Physiol Biochem 2018;51:1287-1300 and Biochemistry \begin{tabular}{l|l} 
DOI: $10.1159 / 000495540$ & $\begin{array}{l}\text { C } 2018 \text { The Author(s). Published by S. Karger AG, Basel } \\
\text { www.karger.com/cpb }\end{array}$
\end{tabular} \\ Vera et al.: Antioxidants For Uremic Endothelial Dysfunction}

morphometric analysis (ImageJ, National Institutes of Health, Bethesda, Maryland, USA). All procedures were performed in duplicate [15].

Activation of p38MAPK and NFKB signaling pathways in endothelial cells

To investigate the effect of the different compounds studied on the activation of the inflammation-related signaling pathways p38MAPK and NFKB, we performed two different approaches: a phosphospecific antibody cell-based ELISA and immunoblotting techniques.

In order to carry out the phosphospecific antibody cell-based ELISA, ECs were seeded in 96-well plates and pretreated with the different flavonoids and mimetics for $24 \mathrm{~h}$. After $4 \mathrm{~h}$ of starving (media with $2 \%$ pooled human sera), ECs were then incubated for $15 \mathrm{~min}$ with the uremic sera in the absence or presence of the selected compounds. Detection of total and phosphorylated protein expression was determined by colorimetric quantification of the relative amount of phosphorylated protein and total target protein, according to the manufacturer's protocol, and results were corrected for cell number [14].

Immunoblotting techniques were then performed to confirm the results obtained by ELISA. In this case, ECs seeded on 6-well plates were pretreated, after starving for $4 \mathrm{~h}$, with the different compounds (24 h), followed by incubation with uremic sera for $15 \mathrm{~min}[13,15]$. Cells were lysed with Laemmli buffer $(125$ $\mathrm{mmol} / \mathrm{l}$ of Tris- $\mathrm{HCl}, 2 \% \mathrm{SDS}, 5 \%$ glycerol, and $0.003 \%$ bromophenol blue), sonicated for 15 sec to shear DNA and reduce viscosity, and heated to $90^{\circ} \mathrm{C}$ for $5 \mathrm{~min}$. Protein concentrations of the supernatants were determined using the Bradford's method. Samples were resolved by $10 \%$ sodium dodecyl sulphate polyacrylamide gel (SDS-PAGE) and proteins were transferred to nitrocellulose membranes. After blocking with $2 \%$ BSA, membranes were probed with the specific primary antibodies phosphorylated p38MAPK (Thr180 and Tyr182), phosphorylated IKBand $\beta$-actin, used as loading control. Considering that translocation of NFKB to the nucleus is preceded by the phosphorylation and degradation of IKB, we decided to analyze the phosphorylation of the IKBprotein in the presence of N-acetyl-leucyl-leucyl-norleucinal (ALLN) which blocks IKBdegradation by the $26 \mathrm{~S}$ proteasome [14]. Following extensive washing, membranes were incubated with a peroxidase-conjugated anti-rabbit immunoglobulin $\mathrm{G}$ and visualized using the chemiluminiscence technique. Densitometric analysis was performed to quantify the intensity of phosphorylation (ImageJ, National Institutes of Health, Bethesda, Maryland, USA) and results were normalized relative to $\beta$-actin.

\section{Evaluation of intracellular GSH}

To evaluate intracellular levels of GSH, cells were grown in 6-well plates (TPP, Sigma-Aldrich, MO, US) to confluence. Cells were incubated with $20 \%$ uremic or control sera and in presence or absence of ebselen and/or NAC for $24 \mathrm{~h}$. Cells were then washed with PBS and collected with accutase. Cell pellets were deproteinized in cold 5\% sulfosalicylic acid (SSA, Sigma-Aldrich) and centrifuged (2500xg, $5 \mathrm{~min}$ ). Sample supernatants were analyzed using the commercial kit K0006-F1 (Arbor Assays) in a fluorimeter (Fluoroskan FL) following the manufacturer's procedure. Raw data, corrected with respect to the cell number, is expressed as a fold increase of GSH with respect to the control.

\section{Statistics}

Results are expressed as mean \pm standard deviation (SD) of data generated in independent experiments (n) using different cell batches and different pooled serum samples from various patients. Statistical analyses were performed by using ANOVA with the SPSS statistical package 17.0.0 (SPSS Inc, Chicago, IL). Results were considered statistically significant when $\mathrm{p}<0.05$.

\section{Results}

\section{Changes in the expression of ICAM-1 on the endothelial cell surface}

There was an enhanced expression of the adhesion molecule ICAM-1 on the cell surface in response to the uremic sera (U) when compared to control sera (increase of $111 \pm 2 \%$ vs control, $n=5, p<0.01$ ) (Fig. 1). When cells were pretreated with flavonoids, only quercetin had a slight but statistically significant effect on ICAM-1 expression (decrease of $26 \pm 11 \%$ with respect to the uremic condition, $n=5, p<0.05$ ), whereas no remarkable changes were observed when apigenin and genistein were used. In contrast, the antioxidant enzyme mi- 


\section{Cellular Physiology Cell Physiol Biochem 2018;51:1287-1300 and Biochemistry \begin{tabular}{l|l} 
DOI: 10.1159/000495540 & (c) 2018 The Author(s). Published by S. Karger AG, Basel \\
www.karger.com/cpb
\end{tabular}

metics ebselen, EUK134 and EUK118 significantly inhibited the expression of ICAM-1 on the ECs surface exposed to uremic sera, with ICAM-1 expression levels similar to those obtained in control experiments (decreases of $47 \pm 6 \%, 42 \pm 11 \%$ and $53 \pm 6 \%$ vs the uremic condition, respectively, $n=5, p<0.01$ ) (Fig. 1). No changes were observed in control cells after being exposed to the different compounds.

\section{Production of intracellular ROS by endothelial cells}

The incubation of ECs with uremic sera for $15 \mathrm{~min}$ resulted in an increase in the levels of ROS of $117 \pm 3 \%$ compared to control levels ( $n=5$, $p<0.01$ ). Pretreatment of cells with ebselen and quercetin had a remarkably significant inhibitory effect on intracellular ROS generation induced by the uremic sera (decreases of $56 \pm 5 \%$ and $37 \pm 4 \%$ vs the uremic condition, $\mathrm{n}=5, \mathrm{p}<0.01$ ). The inhibitory effect of the antioxidant enzyme mimetics EUK134 and EUK118 was moderate (decreases of $23 \pm 3 \%$ and $26 \pm 2 \%$, respectively, vs the uremic condition, $n=5$, $\mathrm{p}<0.05)$. Genistein induced a significant but less intense reduction $(11 \pm 3 \%$ vs the uremic condition, $n=5, p<0.05$ ), whereas apigenin did not modify ROS production (Fig. 2). No significant changes were observed in control cells in response to the compounds under study.

\section{Modulation of the activation of intracellular protein $p 38 M A P K$}

The exposure of ECs to the uremic sera for 15 min resulted in a significant activation of p38MAPK (increase of $90 \pm 5 \%$ vs control sera, $n=5, p<0.05$ ), this increase in the phosphorylation of p38MAPK was inhibited by pretreating ECs with all the pharmacological compounds under study. The flavonoid apigenin and ebselen induced a potent inhibition of p38MAPK activation (decreases of $37 \pm 19 \%$ and $49 \pm 9 \%$ respectively, vs the uremic condition, $n=5, p<0.01$ ). Pretreatment with quercetin, EUK134 and EUK118 produced a remarkable but less intense reduction of p38MAPK activation (decreases of $32 \pm 16 \%, 26 \pm 14 \%$ and $28 \pm 15 \%$, respectively, vs the uremic group, $\mathrm{p}<0.05$ ). Genistein induced a slight, although statistically significant, decrease of the p38MAPK phosphorylation (decrease of $16 \pm 6 \%$ vs uremic condition, $\mathrm{p}<0.05$ ) (Fig. 3A). Western Blot analysis confirmed the results obtained by ELISA (Fig. 3B). No modifications on the activation of p38MAPK were detected in control cells exposed to the compounds under study.

Fig. 1. Antioxidant enzyme mimetics prevent the increase in the expression of ICAM-1 on the endothelial cell surface induced by uremic sera. ECs were pretreated with apigenin $(25 \mu \mathrm{M})$, genistein $(0.1 \mu \mathrm{M})$, quercetin $(1 \mu \mathrm{M})$, ebselen $(5 \mu \mathrm{M})$, EUK134 (1 $\mu \mathrm{M})$ and EUK118 (5 $\mu \mathrm{M})$ for $24 \mathrm{~h}$ and then stimulated with media containing $20 \%$ different pooled sera from uremic patients or healthy donors. Surface expression of the surface receptor ICAM-1 was explored by immunofluorescence. Micrographs show the ICAM-1 surface expression in ECs exposed to control media (C),
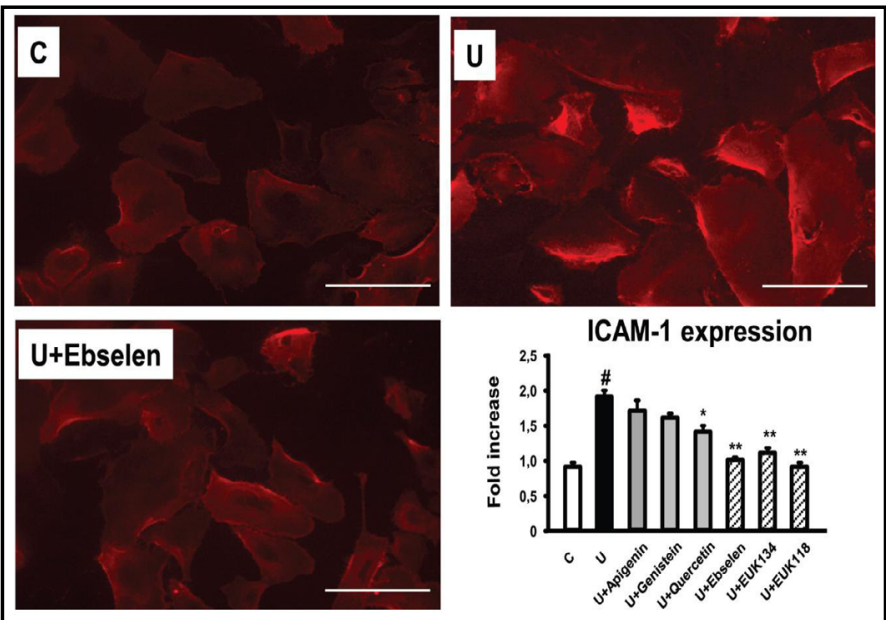
uremic condition $(\mathrm{U})$ and uremic condition treated with ebselen (U+ebselen). Bar diagrams show the effect of the uremic sera (\# $\mathrm{p}<0.05$ vs control) and the different compounds selected $\left(\mathrm{n}=5,{ }^{*} \mathrm{p}<0.05\right.$ and ${ }^{* *} \mathrm{p}<0.01$ vs uremia). 


\section{Cellular Physiology and Biochemistry

Fig. 2. ROS production in endothelial cells exposed to uremic media is inhibited with pharmacological approaches. After pretreatement with apigenin $(25 \mu \mathrm{M})$, genistein $(0.1 \mu \mathrm{M})$, quercetin $(1 \mu \mathrm{M})$, ebselen $(5 \mu \mathrm{M})$, EUK134 $(1 \mu \mathrm{M})$ and EUK $118(5 \mu \mathrm{M})$ for $24 \mathrm{~h}$, ECs were stained with the cell permeable ROS detection reagent $\mathrm{H}_{2}$ DFFDA $(10 \mu \mathrm{M}$, 10min), washed with PBS, and exposed to sera from healthy donors (C) and uremic patients (U), for $30 \mathrm{~min}$. ROS production was detected by fluorescence microscopy. Bar
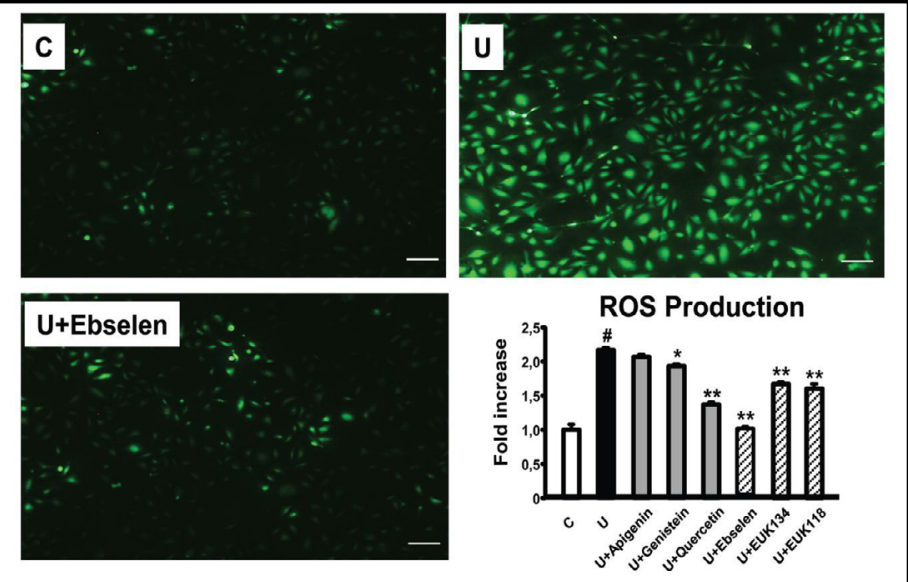
diagrams show the effect of the uremic sera ( $\# p<0.05$ vs control) and the different compounds assayed $\left(\mathrm{n}=5,{ }^{*} \mathrm{p}<0.05\right.$ and ${ }^{* *} \mathrm{p}<0.01$ vs uremia).

Fig. 3. Activation of p38MAPK signaling pathway by uremic sera is inhibited by flavonoids and antioxidant mimetics. ECs were incubated (15 $\mathrm{min})$ with sera from control donors (C), and uremic patients (U) in the absence and presence of apigenin, genistein, quercetin, ebselen, EUK134 and EUK118 (n=5). A. Bar diagrams represent the ratios of phosphorylated p38 MAPK relative to the total protein, obtained from antibody cell-based ELISA technique. B. Phospho-p38 MAPK in ECs was also assessed by Western-

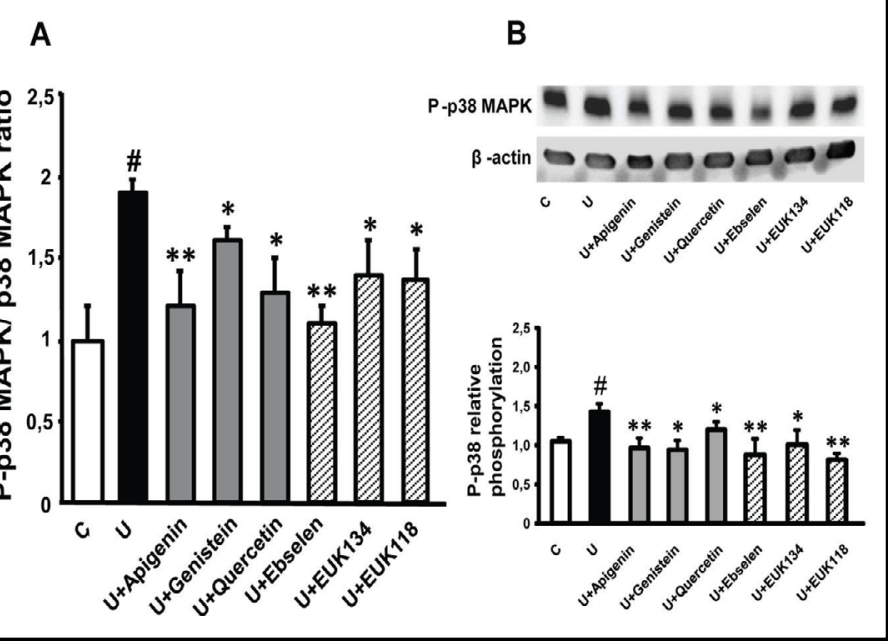
Blot. Images are representative of 4 different experiments. Results were quantified and represented as Mean \pm SD by bar diagram. \# $\mathrm{p}<0.01$ vs control and ${ }^{*} \mathrm{p}<0.05,{ }^{* *} \mathrm{p}<0.01$ vs uremia.

\section{Effect on the NFKB signaling pathway}

Activation of NFKB (p65) protein was significantly higher after exposing ECs to the sera from the uremic patients when compared to the control experiments (increase of $80 \pm 6 \%$ with respect to controls, $n=4, p<0.01$ ) (Fig. 4A). No differences were observed in the phosphorylation levels of NFKB (p65) when ECs were previously treated with the flavonoids assayed. NFKB activation was notably attenuated by ebselen and EUK118 (decreases of $21 \pm$ $7 \%$ and $17 \pm 7 \%$ vs the uremic condition, respectively, $n=4, p<0.05$ ) and the most remarkable reduction was observed in the presence of EUK134 (decrease of $31 \pm 16 \%$ vs uremic condition, $\mathrm{n}=4, \mathrm{p}<0.01$ ). Western Blot analysis of IKBphosphorylation showed similar results as those obtained with the cell-based ELISA assay (Fig. 4B). Exposure of control cells to the compounds under study did not induce any modification in the IKBphosphorylation. 
Fig. 4. Activation of $N F \kappa B$ (p65) signaling pathway by uremic sera is prevented by antioxidant enzyme mimetics. ECs were incubated (15 min) with sera from control donors (C), and uremic patients (U) in the absence and presence of apigenin, genistein, quercetin, ebselen, EUK134 and EUK118 (n=4). A. Ratios of phosphorylated NFKB (p65) relative to the total protein. Data are corrected for cell number and are represented as Mean \pm SD.

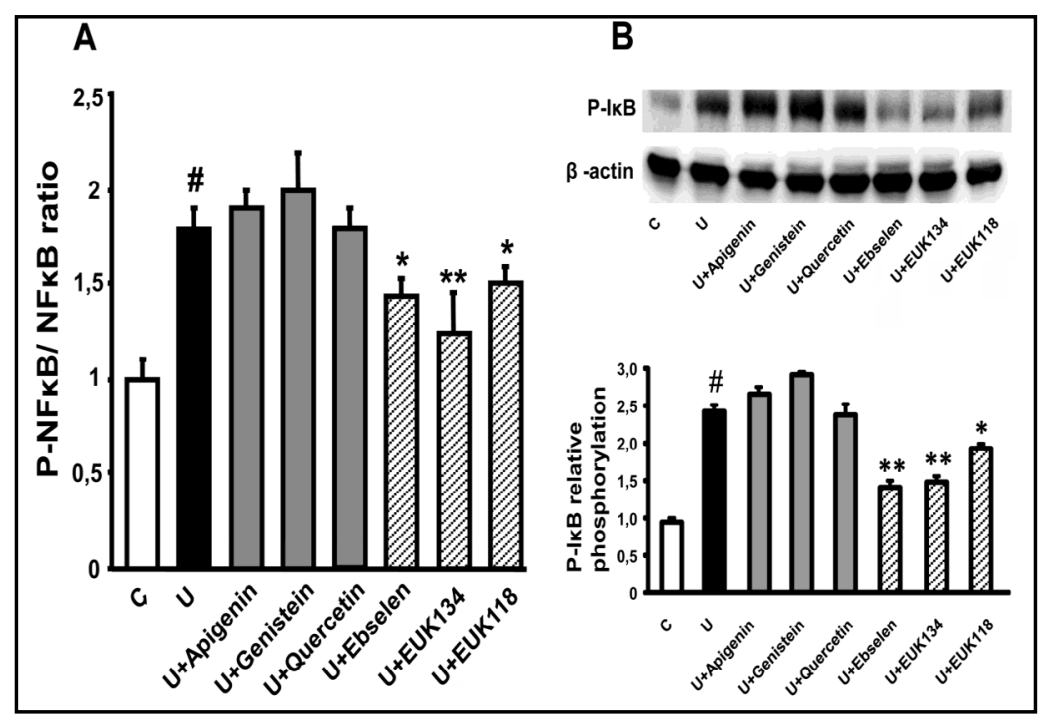
B. ІкB was assessed by Western-Blot in ECs previously treated with ALLN $\left(50 \mu \mathrm{g} / \mathrm{ml}, 30 \mathrm{~min}, 37^{\circ} \mathrm{C}\right)$. Images are representative of 4 different experiments. \# $\mathrm{p}<0.01$ vs control and ${ }^{*} \mathrm{p}<0.05$, ${ }^{* *} \mathrm{p}<0.01$ vs uremia.

Anti-inflammatory and antioxidant effects of NAC on endothelial cells

NAC demonstrated both anti-inflammatory and antioxidant properties in ECs exposed to the uremic condition, showing effects comparable to ebselen regarding inflammation markers and even greater with respect to the antioxidant effect. NAC was able to inhibit the expression of ICAM-1 (decrease of $49 \pm 8 \%$ vs the uremic condition, $n=4, p<0.01$ ), intracellular ROS generation (decrease of $62 \pm 12 \%$ vs the uremic condition, $\mathrm{n}=4$, $\mathrm{p}<0.01$ ), phosphorylation of p38MAPK (decrease of $47 \pm 13 \%$ vs the uremic

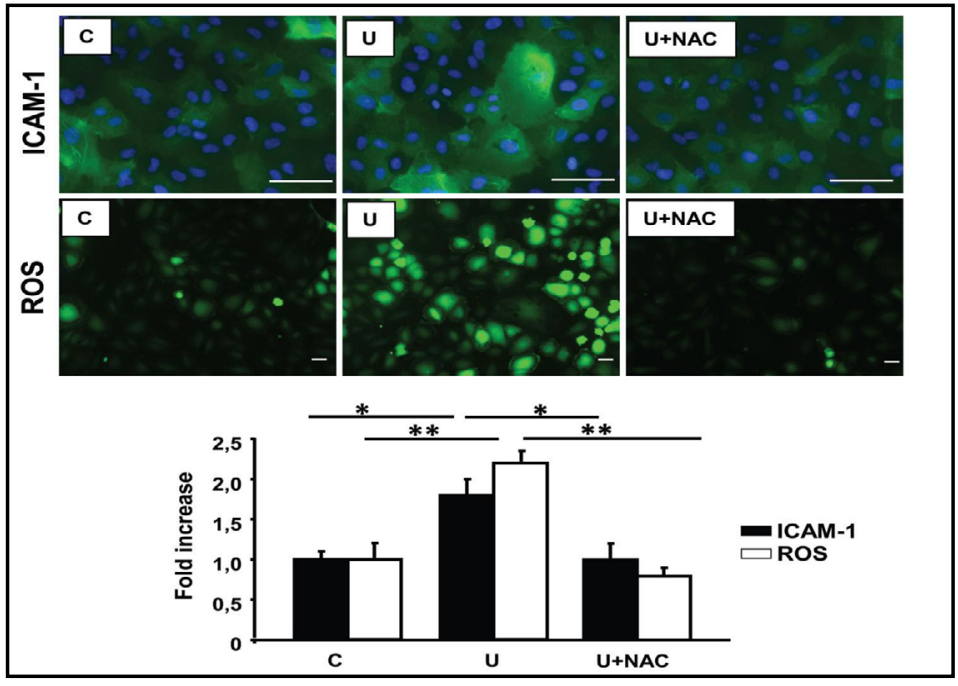

Fig. 5. Anti-inflammatory and antioxidant effects of NAC on endothelial cells exposed to uremic sera. Micrographs show ICAM-1 surface expression and ROS production in ECs exposed to control media (C), uremia (U) and uremia treated with NAC (U+NAC). Bar diagrams show the effect of the uremic sera (\# $p<0.05$ vs control) and the NAC treatment $\left({ }^{*} \mathrm{p}<0.05,{ }^{* *} \mathrm{p}<0.01\right.$ vs uremia) $(\mathrm{n}=4)$. NAC $(10 \mathrm{mM})$ inhibited phosphorylation of p38MAPK and activation of NFKB $(n=4)$. condition, $\mathrm{n}=5, \mathrm{p}<0.01$ ), and NFKB activation (decrease of $31 \pm 8 \%$ vs the uremic condition, $n=4, p<0.01$ ) (Fig. 5).

Changes of GSH levels in endothelial cells treated with ebselen and NAC

Cells grown under uremic conditions showed slightly higher GSH concentrations than control cells ( $\%$ of increase of $28 \pm 17 \%$ vs. control, $n=5$ ). Ebselen pretreatment increased GSH levels in both control and uremic cells ( $\%$ of increase with respect to their baseline condition of $32 \pm 3 \%, n=5, p<0.01$, and of $18 \pm 14 \%, n=5, p<0.05$, respectively). NAC also raised GSH levels in cell culture in both the control and the uremic conditions (increases of $24 \pm$ 


\section{Cellular Physiology Cell Physiol Biochem 2018;51:1287-1300

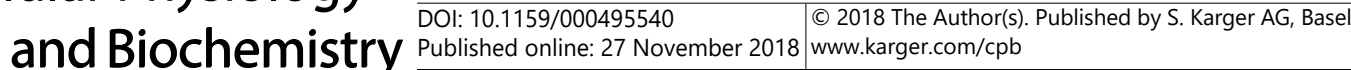 Vera et al.: Antioxidants For Uremic Endothelial Dysfunction}

$3 \%, \mathrm{n}=5, \mathrm{p}<0.01$ and $32 \pm 15 \%, \mathrm{n}=5, \mathrm{p}<0.05$, respectively). Coincubation with ebselen and NAC together in the culture media increased GSH in ECs both in control and uremic cells $47 \pm 13 \%$, $n=5, p<0.05$ and $52 \pm 7 \%, n=5, p<0.01$, respectively) (Fig. 6).

\section{Discussion}

In the present study we confirm that endothelial dysfunction in uremia is associated with a proinflammatory phenotype and enhanced oxidative stress, as we and others have previously demonstrated [13-16, 28, 35-37]. Furthermore, we have shown the different protective effects of several anti-inflammatory and antioxidant strategies. While some of the flavonoids assayed exhibited moderate anti-inflammatory and antioxidant effects, the antioxidant enzyme mimetics of SOD and GPx, and NAC, were more effective at inhibiting the expression of adhesion molecules on the cell surface, ROS production,

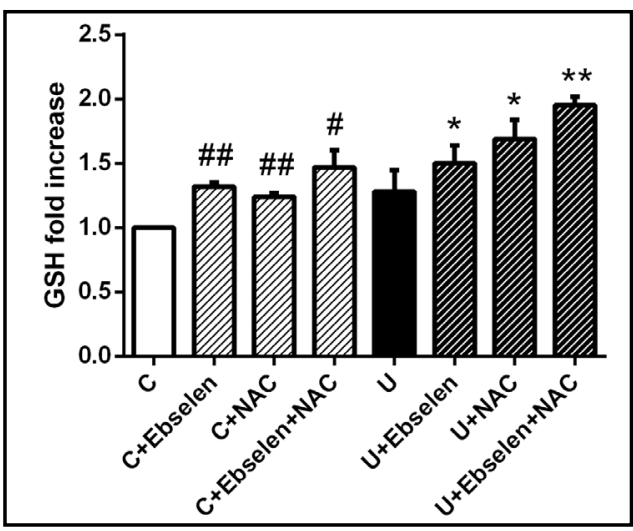

Fig. 6. GSH restoration is promoted by ebselen and NAC in endothelial cell cultures. Endothelial cell cultures were grown in the presence of control or uremic sera for $24 \mathrm{~h}$. Bar diagrams represent GSH levels with respect to the control. The effect of the compounds was statistically compared with respect to their respective basal situation (\# $\mathrm{p}<0.05$ and \#\# $\mathrm{p}<0,01$ vs control; ${ }^{*} \mathrm{p}<0.05,{ }^{* *} \mathrm{p}<0.01$ vs uremia). NAC $(10 \mathrm{mM})$ and ebselen $(5 \mu \mathrm{M})$. and the activation of the inflammation-related pathways p38MAPK and NFKB. Interestingly, the enhancement of the GPx pathway, either by a mimetic of the enzyme activity (ebselen) or by promoting the restoration of the reduced glutathione (NAC), proved to be the most effective strategy to protect the endothelium from the deleterious effect of the uremic milieu.

An imbalance between oxidative stress and the antioxidant mechanisms, together with the chronic inflammation present in uremia, are likely to play a major role in the development of an accelerated atherosclerosis and enhanced cardiovascular risk in long-term dialysis patients [4, 6-8]. Therefore, the modulation of inflammation and oxidative stress appears to be a promising strategy to prevent endothelial damage in this condition. Based on our previous evidence $[13,15,35,36]$, we aimed to investigate the potential protective effect of different compounds with antioxidant and/or anti-inflammatory properties on the CKDinduced endothelial dysfunction.

Flavonoids possess certain antitumoral, antioxidant, and anti-inflammatory activities $[37,38]$. However, there are several limitations to assay these compounds as potential pharmacological targets: the large number of the identified flavonoids, their different chemical structures and the high doses required, difficult to achieve with a regular diet. In our study, only the flavonol quercetin prevented ROS production, being the only flavonoid tested able to also reduce the expression of the adhesion receptor ICAM-1, and the activation of the inflammation-related pathways p38MAPK and NFKB. Although the isoflavone genistein reduced the generation of ROS and the phosphorylation of p38MAPK, it failed to prevent NFKB activation and ICAM-1 expression in uremic ECs. The flavone apigenin did not show any antioxidant effect on ECs exposed to the conditions assayed. In contrast with our results, there are studies reporting beneficial antioxidant and anti-inflammatory effects of genistein and apigenin in other situations. These effects include the prevention of LDL oxidation, the attenuation of ROS production, the inhibition of NFKB signaling pathway and the expression of cell adhesion molecules [39-42]. The discrepancies with the results found in our study suggest that the effect of these compounds may depend on several factors, including dosage, type of stimuli and the heterogeneity of ECs lines used in the in vitro studies.

Uremic patients exhibit an impaired production of endogenous antioxidant defenses and accumulate uremic toxins that induce oxidative stress [43-46]. Moreover, the accumula- 
tion of endogenous ROS results in the activation of intracellular signaling pathways involved in proliferation, survival, and inflammatory responses [46]. The main intracellular antioxidant enzymes include SOD and GPx, among others. Recently, a group of cell-permeable and low molecular weight antioxidant enzyme mimetics are acquiring growing interest for the prevention of complications related to conditions associated with enhanced oxidative stress. Of those, EUK118 and EUK134 show SOD enzyme mimetic activity; while ebselen, an organoselenium compound, catalyzes the reduction of ROS in a manner similar to GPx. This last compound also reacts with the thioredoxin system and acts as a dehydroascorbic acid reductase mimetic. Our present results clearly demonstrated that the antioxidant enzyme mimetics studied exhibit not only free radical scavenging activity, but also anti-inflammatory effects, with a significant inhibition of the activation of the signaling pathways p38MAPK and NFKB, together with the reduction in the expression of adhesion molecules on the EC surface when cells were exposed to the uremic condition.

Interestingly, ebselen and NAC showed the most potent protective antioxidant and antiinflammatory effects on ECs exposed to uremic milieu. Ebselen appears to be a promising drug because of the multiplicity of its mechanisms for inhibiting free radical-induced injury coupled with a rapid absorption following oral administration. However, as ebselen has been shown to have significant cellular toxicity, novel ebselen-based agents are being developed [47]. NAC is currently used as an antioxidant and a mucolytic agent. The therapeutic potential of NAC is currently being investigated as an antidote for specific toxins, as a bioprotective agent against oxidative stress and ischemic injury, and as a treatment for certain mental and physical disorders. Although reduced glutathione is the most important intracellular antioxidant, oral administration of NAC is even more efficient than direct glutathione administration [48]. Further, NAC stimulates glutathione-S-transferase activity, promotes detoxification and acts as a scavenger of free radicals due to its direct interaction with ROS [49]. GPx pathway is largely known to minimize lipid peroxidation of cellular membranes and other biological processes associated with oxidative stress. Thus, the potentiation of this antioxidant pathway could be a promising strategy to prevent uremia-induced endothelial dysfunction. In fact, a decrease in plasma levels of GSH or GPx have been shown in CKD patients [9, 4547], and a decreased GSH/GSSG ratio in ECs exposed to uremic media have been previously reported [35]. This later finding is in contrast to our results, since a slight increase in GSH in uremic endothelial cells has been observed, which could be a compensatory response against the prooxidant state present in endothelial cells in response to the uremic milieu. However, and in agreement with the previous and another study, uremic endothelial dysfunction was improved by NAC $[28,35]$, as well as by ebselen. Furthermore, the combined effect of ebselen and NAC on GSH levels were additive in uremic endothelial cells, suggesting a beneficial effect of enhancing the GPx pathway in CKD-induced ED.

The main limitations of the present study are that the concentrations used in these experiments were based on cell viability analysis and not plasma levels physiologically or pharmacologically achieved. The results of this in vitro model should be confirmed in in vivo studies.

The results of the present study indicate that uremic endothelial dysfunction can be minimized through an antioxidant strategy. While the benefit of flavonoids is unclear and may be controversial due to the concentrations needed to cause a beneficial effect, the changes observed with the antioxidant enzyme mimetics and NAC indicate that these compounds may be promising therapeutic strategies to provide endothelial protection against the uremic insult. Specifically, the activation of the glutathione peroxidase pathway, either by using an enzyme mimetic and/or by providing the substrate for GSH through NAC, reduce not only the oxidative stress but also the inflammatory process induced by the uremic milieu on the endothelium.

Basic and clinical investigations provide strong evidence of the development of an endothelial dysfunction in chronic kidney disease (CKD), leading to accelerated atherosclerosis and increased cardiovascular risk. However, a pharmacological holistic approach to reduce the broad features involved in vascular remodeling in CKD remains to be discovered. The

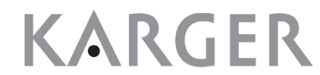




\section{Cellular Physiology Cell Physiol Biochem 2018;51:1287-1300

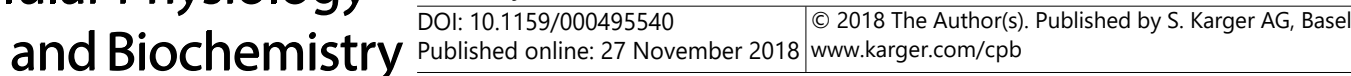 \\ Vera et al.: Antioxidants For Uremic Endothelial Dysfunction}

results of our study provide a new approach for the prevention and treatment of the CKDrelated endothelial dysfunction, and perhaps can arise as a useful strategy to reduce the incidence of cardiovascular events in this high risk population.

\section{Abbreviations}

AEM (Antioxidant enzyme mimetic); ECs (endothelial cells); ED (endothelial dysfunction); CVD (cardiovascular disease); CKD (chronic kidney disease); GDP (glucose degradation products); GPx (glutathione peroxidase); HMGB1 (high mobility group box-1 protein); ICAM-1 (intercellular adhesion molecule 1); MAPK (mitogen-activated protein kinase); NAC (N-acetylcysteine); ROS (reactive oxygen species); SOD (superoxide dismutase); TLR4 (tolllike receptor 4); U (uremic sera).

\section{Acknowledgements}

This work has been partially supported by Integrated Project in Health Institutes (PIE15/00027) and Technology Development Projects in Health 2016 (DTS16/00133) from the Instituto de Salud Carlos III, Spanish Government; 2017-SGR671 from Generalitat de Catalunya, Jazz Pharmaceuticals Plc (IST-16-10355), grant from the German José Carreras Leukaemia Foundation (11R/2016) and CERCA Programme of the Generalitat de Catalunya.

Research by the group of JR is supported by grants from Instituto de Salud Carlos III and Fundación Séneca (PI14/01956, CB15/00055).

\section{Disclosure Statement}

No competing financial interests exist.

\section{References}

1 Aird WC: Phenotypic heterogeneity of the endothelium: II. Representative vascular beds. Circ Res 2007;100:174-190.

-2 Le Brocq M, Leslie SJ, Milliken P, Megson IL. Endothelial dysfunction: From molecular mechanisms to measurement, clinical implications, and therapeutic opportunities. Antioxid Redox Signal 2008;10:16311674.

3 Grassi D, Desideri G, Ferri C. Cardiovascular risk and endothelial dysfunction: the preferential route for atherosclerosis. Curr Pharm Biotechnol 2011;12:1343-1353.

4 Zoccali C, Vanholder R, Massy ZA, Ortiz A, Sarafidis P, Dekker FW, Fliser D, Fouque D, Heine GH, Jager KJ, Kanbay M, Mallamaci F, Parati G, Rossignol P, Wiecek A, London G: The systemic nature of CKD. Nat Rev Nephrol 2017;13:344-358.

5 Gris JC, Branger B, Vécina F, Al Sabadani B, Fourcade J, Schved JF: Increased cardiovascular risk factors and features of endothelial activation and dysfunction in dialyzed uremic patients. Kidney Int 1994;46:807813.

6 Zimmermann J, Herrlinger S, Pruy A, Metzger T, Wanner C: Inflammation enhances cardiovascular risk and mortality in hemodialysis patients. Kidney Int 1999;55:648-658.

-7 Stenvinkel P: New insights on inflammation in chronic kidney disease-genetic and non-genetic factors. Nephrol Ther 2006;2:111-119.

-8 Himmelfarb J, Stenvinkel P, Ikizler TA, Hakim RM: Perspectives in renal medicine: The elephant in uremia: Oxidant stress as a unifying concept of cardiovascular disease in uremia. Kidney Int 2002;62:1524-1538. 


\section{Cellular Physiology Cell Physiol Biochem 2018;51:1287-1300 and Biochemistry DOl: 10.1159/000495540 20102018 The Author(s). Published by S. Karger AG, Basel

Vera et al.: Antioxidants For Uremic Endothelial Dysfunction

9 Duni A, Liakopoulos V, Rapsomanikis KP, Dounousi E: Chronic Kidney Disease and Disproportionally Increased Cardiovascular Damage: Does Oxidative Stress Explain the Burden?.Oxid Med Cell Longev.2017;2017:9036450.

10 Sato A, Okada M, Shibuya K, Watanabe E, Seino S, Narita Y, Narita Y, Shibui S, Kayama T, Kitanaka C: Pivotal role for ROS activation of p38 MAPK in the control of differentiation and tumor-initiating capacity of glioma-initiating cells. Stem Cell Res 2014;12:119-131.

11 Palomo M, Diaz-Ricart M, Carbo C, Rovira M, Fernandez-Aviles F, Escolar G, Eissner G, Holler E, Carreras E: The Release of Soluble Factors Contributing to Endothelial Activation and Damage after Hematopoietic Stem Cell Transplantation Is Not Limited to the Allogeneic Setting and Involves Several Pathogenic Mechanisms. Biol Blood Marrow Transplant 2009;15:537-546.

12 Hanzu FA, Palomo M, Kalko SG, Parrizas M, Garaulet M, Escolar G, Gomis R, Diaz-Ricart M: Translational evidence of endothelial damage in obese individuals: Inflammatory and prothrombotic responses. J Thromb Haemost 2011;9:1236-1245.

13 Serradell M, Diaz-Ricart M, Cases A, Petriz J, Ordinas A, Escolar G: Uraemic medium accelerates proliferation but does not induce apoptosis of endothelial cells in culture. Nephrol Dial Transplant 2003;18:10791085.

14 Carbo C, Arderiu G, Escolar G, Fusté B, Cases A, Carrascal M, Abian J, Diaz-Ricart M: Differential Expression of Proteins From Cultured Endothelial Cells Exposed to Uremic Versus Normal Serum. Am J Kidney Dis 2008;51:603-612.

15 Caballo C, Palomo M, Cases A, Galan AM, Molina P, Vera M, Bosch X, Escolar G, Diaz-Ricart M: NFkB in the Development of Endothelial Activation and Damage in Uremia: An In vitro Approach. PLoS One 2012;7:e43374.

16 Martin-Rodriguez S, Caballo C, Gutierrez G, Vera M, Cruzado JM, Cases A, Escolar G, Diaz-Ricart M: TLR4 and NALP3 inflammasome in the development of endothelial dysfunction in uraemia. Eur J Clin Invest 2015;45:160-169.

17 Wanner C: Chronic kidney disease and statin therapy: To treat or not to treat? Eur Heart J 2013;34:17721774.

18 Agarwal R, Sinha AD, Pappas MK, Abraham TN, Tegegne GG: Hypertension in hemodialysis patients treated with atenolol or lisinopril: a randomized controlled trial. Nephrol Dial Transplant 2014;29:672-681.

19 Iseki K, Arima H, Kohagura K, Komiya I, Ueda S, Tokuyama K, Shiohira Y, Uehara H, Toma S: Effects of angiotensin receptor blockade (ARB) on mortality and cardiovascular outcomes in patients with long-term haemodialysis: a randomized controlled trial. Nephrol Dial Transplant 2013;28:1579-1589.

20 Manach C, Scalbert A, Morand C, Remesy C, Jimenez L: Polyphenols: Food sources and Bioavailability. Am J Clin Nutr 2004;79:727-747.

21 Mennen LI, Sapinho D, de Bree A, Arnault N, Bertrais S, Galan P, Hercberg S: Consumption of foods rich in flavonoids is related to a decreased cardiovascular risk in apparently healthy French women. J Nutr 2004;134:923-926.

22 Baker K, Marcus CB, Huffman K, Kruk H, Malfroy B, Doctrow SR: Synthetic combined superoxide dismutase/catalase mimetics are protective as a delayed treatment in a rat stroke model: a key role for reactive oxygen species in ischemic brain injury. J Pharmacol Exp Ther 1998;284:215-221.

23 Hosakote YM, Komaravelli N, Mautemps N, Liu T, Garofalo RP, Casola A: Antioxidant mimetics modulate oxidative stress and cellular signaling in airway epithelial cells infected with respiratory syncytial virus. AJP Lung Cell Mol Physiol 2012;303:L991-L1000.

24 Chew P, Yuen DYCC, Koh P, Stefanovic N, Febbraio MA, Kola I, Cooper ME, de Haan JB: Site-specific antiatherogenic effect of the antioxidant ebselen in the diabetic apolipoprotein E-deficient mouse. Arterioscler Thromb Vasc Biol 2009;29:823-830.

25 Coombes JS, Fassett RG: Antioxidant therapy in hemodialysis patients: A systematic review. Kidney Int 2012;81:233-246.

26 Tepel M, Van der Giet M, Statz M, Jankowski J, Zidek W: The antioxidant acetylcysteine reduces cardiovascular events in patients with end-stage renal failure: A randomized, controlled trial. Circulation 2003;107:992-995.

-27 Sahin G, Yalcin AU, Akcar N: Effect of N-acetylcysteine on endothelial dysfunction in dialysis patients. Blood Purif 2007;25:309-315. 


\section{Cellular Physiology Cell Physiol Biochem 2018;51:1287-1300 and Biochemistry \begin{tabular}{l|l} 
DOI: 10.1159/000495540 & (c) 2018 The Author(s). Published by S. Karger AG, Basel
\end{tabular} \\ Vera et al.: Antioxidants For Uremic Endothelial Dysfunction}

28 Shang F, Wang S-C, Hsu C-Y, Miao Y, Martin M, Yin Y, Wu CC, Wang YT, Wu G, Chien S, Huang HD, Tarng DC, Shiu YT, Cheung AK, Huang PH, Chen Z, Shyy JY: MicroRNA-92a Mediates Endothelial Dysfunction in CKD. J Am Soc Nephrol 2017;28:3251-3261.

29 Rushworth GF, Megson IL: Existing and potential therapeutic uses for N-acetylcysteine: the need for conversion to intracellular glutathione for antioxidant benefits. Pharmacol Ther 2014;141:150-159.

-30 Samuni Y, Goldstein S, Dean OM, Berk M: The chemistry and biological activities of N-acetylcysteine. Biochim Biophys Acta - Gen Subj 2013;1830:4117-4129.

-31 Gressier B, Cabanis A, Lebegue S, Brunet C, Dine T, Luyckx M, Cazin M, Cazin JC: Decrease of hypochlorous acid and hydroxyl radical generated by stimulated human neutrophils: comparison in vitro of some thiolcontaining drugs. Methods Find Exp Clin Pharmacol 1994;16:9-13.

-32 Jaffe EA, Nachman RL, Becker CG, Minick CR: Culture of human endothelial cells derived from umbilical veins. Identification by morphologic and immunologic criteria. J Clin Invest 1973;52:2745-2756.

-33 Aruoma OI, Halliwell B, Hoey BM, Butler J: The antioxidant action of N-acetylcysteine: Its reaction with hydrogen peroxide, hydroxyl radical, superoxide, and hypochlorous acid. Free Radic Biol Med 1989;6:593597.

-34 Spagnuolo G, D’Anto V, Cosentino C, Schmalz G, Schweikl H, Rengo S: Effect of N-acetyl-L-cysteine on ROS production and cell death caused by HEMA in human primary gingival fibroblasts. Biomaterials 2006;27:1803-1809.

-35 Rodrigues SD, França KC, Dallin FT, Fujihara CK, Nascimento AJ, Pecoits-Filho R, Nakao LS: N-acetylcysteine as a potential strategy to attenuate the oxidative stress induced by uremic serum in the vascular system. Life Sci 2015;121:110-116.

-36 Serradell M, Diaz-Ricart M, Cases A, Zurbano MJ, Aznar-Salatti J, Lopez-Pedret J, Ordinas A, Escolar G: Uremic medium disturbs the hemostatic balance of cultured human endothelial cells. Thromb Haemost 2001;86:1099-1105.

37 Serradell M, Diaz-Ricart M, Cases A, Zurbano MJ, Lopez-Pedret J, Arranz O, Ordinas A, Escolar G: Uremic medium causes expression, redistribution and shedding of adhesion molecules in cultured endothelial cells. Haematologica 2002;87:1053-1061.

38 Gerritsen ME, Carley WW, Ranges GE, Shen CP, Phan SA, Ligon GF, Perry CA: Flavonoids inhibit cytokineinduced endothelial cell adhesion protein gene expression. Am J Pathol 1995;147:278-292.

39 Read MA: Flavonoids: naturally occurring anti-inflammatory agents. Am J Pathol 1995;147:235-227.

40 Wang J, Liao Y, Fan J, Ye T, Sun X, Dong S: Apigenin inhibits the expression of IL-6, IL-8, and ICAM-1 in DEHPstimulated human umbilical vein endothelial cells and in vivo. Inflammation 2012;35:1466-1476.

41 Siow RCM, Li FYL, Rowlands DJ, de Winter P, Mann GE: Cardiovascular targets for estrogens and phytoestrogens: transcriptional regulation of nitric oxide synthase and antioxidant defense genes. Free Radic Biol Med 2007;42:909-925.

42 Palmieri D, Perego P, Palombo D: Apigenin inhibits the TNF $\alpha$-induced expression of eNOS and MMP-9 via modulating Akt signalling through oestrogen receptor engagement. Mol Cell Biochem 2012;371:129-136.

43 Takano-Ishikawa Y, Goto M, Yamaki K: Inhibitory Effects of Several Flavonoids on E-selectin Expression on Human Umbilical Vein Endothelial Cells Stimulated by Tumor Necrosis Factor- $\alpha$. Phytother Res 2003;17:1224-1227.

44 Chao CT, Chiang C-KK: Uremic toxins, oxidative stress, and renal fibrosis: An interwined complex. J Ren Nutr 2015;25:155-159.

45 Tbahriti HF, Kaddous A, Bouchenak M, Mekki K: Effect of Different Stages of Chronic Kidney Disease and Renal Replacement Therapies on Oxidant-Antioxidant Balance in Uremic Patients. Biochem Res Int 2013;2013:358985.

-46 Annuk M, Fellstrom B, Akerblom 0, Linde T, Fellstrom B. Oxidative stress markers in pre-uremic patients. Clin Nephrol 2001;56:308-314.

47 Roxborough HE, Mercer C, McMaster D, Maxwell AP, Young IS. Plasma glutathione peroxidase activity is reduced in haemodialysis patients. Nephron 1999;81:278-283.

48 Deanfield JD, Halcox JP, Rabelink TJ. Endothelial function and dysfunction: Testing and clinical relevance. Circulation 2007;115:1285-1295.

49 Azad GK, Tomar RS: Ebselen, a promising antioxidant drug: mechanisms of action and targets of biological pathways. Mol Biol Rep 2014;41:4865-4879. 
Cellular Physiology Cell Physiol Biochem 2018:51:1287-1300 \begin{tabular}{ll|l} 
and Biochemistry & $\begin{array}{l}\text { DOl: 10.1159/000495540 } \\
\text { Published online: 27 November } 2018\end{array}$ & $\begin{array}{l}\text { @ } 2018 \text { The Author(s). Published by S. Karger AG, Basel } \\
\text { www.karger.com/cpb }\end{array}$ \\
\hline
\end{tabular}

Vera et al.: Antioxidants For Uremic Endothelial Dysfunction

50 Witschi A, Reddy S, Stofer B, Lauterburg BH: The systemic availability of oral glutathione. Eur J Clin Pharmacol 1992;43:667-669.

51 Dodd S, Dean O, Copolov DL, Malhi GS, Berk M: N-acetylcysteine for antioxidant therapy: pharmacology and clinical utility. Expert Opin Biol Ther 2008;8:1955-1962. 